\title{
Accompaniment program for university students from vulnerable groups at the Escuela Politécnica Nacional
}

\author{
Iván P. Sandoval, MSc, Galo C. Prócel, MSc, Joseph J. Sánchez, MSc, Iliana E. Carrera, Eng, Andrés Proaño Eng. \\ Escuela Politécnica Nacional, Ecuador, \\ ivan.sandoval@epn.edu.ec, galo.procel@epn.edu.ec, joseph.sanchezb@epn.edu.ec, iliana.carreraf@epn.edu.ec, \\ andres.proanof@epn.edu.ec
}

\section{ABSTRACT:}

Since 2014, the "Secretaría Nacional de Educación Superior, Ciencia, Tecnología e Innovación (SENESCYT)," (the National Secretariat for Higher Education, Science, Technology and Innovation) implemented an affirmative action policy called "Política de Cuotas" (Quota Policy), in order to fulfill the "Ley Orgánica de Educación Superior" (Organic Law of Higher Education), which states that "Instituciones de Educación Superior (IES)” (Institutions of Higher Education) must implement mandatory policies in favor of historically discriminated and vulnerable groups.

Students from these groups, who are characterized by low academic performance, have high rates of academic loss and dropout, which makes this policy inefficient, generating socioeconomic losses to the State, the Institutions, and the population.

Because of this, the "Escuela Politécnica Nacional (EPN)", through the "Departamento de Formación Básica (DFB)", implemented a program of academic accompaniment for these students who belong to vulnerable groups, improving their academic performance index, however this students presented high dropout rate due to the economic problems, lack of time form students, and insufficient pedagogical training of the tutors.

Keywords: academic accompaniment, inclusion, vulnerable groups, tutorials

\section{INTRODUCTION}

"It is defined as vulnerable people those have diminished, for different reasons, their abilities to face the eventual injuries of their human rights. The vulnerability is associated with a specific condition that allows the individual to be identified as a member of a certain group, that as a general rule, it is in conditions of inequality with respect to the majority group."[1]

The Inter-American Development Bank (IDB), in the Latin American context, exposes as potential groups at risk, or at social exclusion, the indigenous groups, physically disabled people, and population with a very low human development index (HDI) and women [2].

Digital Object Identifier (DOI): http://dx.doi.org/10.18687/LACCEI2018.1.1.238 ISBN: 978-0-9993443-1-6

ISSN: $2414-6390$
Bashir and Luque (2012) classify limitations as: Long term (e.g. financial problems); and, short term (e.g., family background, previous knowledge in education) that impede the access to higher education. [3]

In Latin America, it is evident that the efforts are oriented to the widening of basic and middle education, through policies aimed to improve the excellent quality and with this the attention to social groups that for their economic, geographic, ethnic or cultural vulnerability, present greater problems in accessing secondary and higher education. [4]

The International Institute for Higher Education in Latin America and the Caribbean (IESALC), between 2000 and 2005, diagnosed the factors and the magnitude of dropout in public and private universities in Latin America. Their results show that, with the exception of Cuba, only $43 \%$ of the people who enter higher education centers facilities graduate in the period established to do so. According to Gairín et al. (2014), the rates of graduates and academic success are indexes of social and cultural development, and the positive effect in the evolution in the quality of life of modern societies and their citizens [5].

Ecuador, in the quest to include historically excluded groups, declares in its Constitution that "The state will recognize young people as strategic actors of the country's development, and will guarantee them education, health, housing, recreation, sports, free time, freedom of expression and association. The State will encourage their incorporation into work under fair and dignified conditions, with emphasis on training, guaranteeing access to first employment and promoting their entrepreneurial skills."[6]

The IES with the goal of making policies in favor of discriminated groups, and in compliance with the "Ley Orgánica de Educación Superior (LOES)", have elaborated an affirmative action policy that implements the "Política de Cuotas" project developed by SENESCYT. The affirmative action policy has been working since 2014 [7].

The project has benefited 16,414 citizens, including indigenous people, Afro-Ecuadorians, people with some type of disability, beneficiaries of the government bond, 
refugees with ID card and those who belong to the lowest socioeconomic quintiles.

The "Política de Cuotas" project has, as its principle, the social inclusion, which strengthens the quality and democracy in education. In this way, socioeconomic factors, ethnicity, disability, place of residence, cease to be an impediment for young people, in Ecuador, to gain access, maintain and complete their academic studies.

The "Politica de Cuotas" project, promoted by the Ecuadorian Government, has strengthened the access to higher education for discriminated groups, however, that the students from these groups, keep studying, is a challenge for universities. SENESCYT through an algorithm identifies students from vulnerable groups and assigns them up to $15 \%$ of the offered quotes.

The low academic performance in vulnerable groups at the beginning of the first years of university, is due to the lack of study habits and deficiencies in the handling of the contents. In addition, the transition/adaptation to the university is a stressful process because students are confronted with a cognitive complexity to which they have not been exposed to during the high school stage. [8]

The "Centro de Investigación en Creatividad y Educación Superior (CICES)", indicates that the access to universities for students belonging to vulnerable groups is the first encounter with the higher education system, since most of these students are the first generation of their families who can access to the university. Factors such as distance from hometown, ignorance of the city or area where they study, long journeys of transfer (commute), loss of reference groups and the need to generate new friendships and academic work groups, are challenges for students that come from underprivileged sectors. [9]

According to Cruz y Días (2012), academic performance is the result of a set of psychological, social and economic factors, which affect to a different degree, the adequate development of students [10].

In the case of the EPN, the low academic performance and the high dropout rate of students from vulnerable groups was a concern of the DFB, which is why a program was developed to fortify the knowledge acquired in their training and improve the results of their academic performance, the inclusion program was implemented to monitor and support the students of the "Política de Cuotas" project.

The objective of the program is to train and give academic follow-up to students who enter to the "Escuela Politécnica Nacional". The purpose of this document is to present the results obtained during the implementation of this program. Program is intended to help students from vulnerable groups.

The present work has been structured as: Methodology (Section II), Results' Analysis (Section III), Conclusions and Recommendations (Section IV). All in accordance with the provisions of LACCEI.

\section{METHODOLOGY}

For the present work, a documented and statistical analysis was carried out, this analysis revealed the reality of the vulnerable groups in the "Curso de Nivelación" of the "Escuela Politécnica Nacional". The data was obtained from the SENESCYT and the "Sistema de Administración Estudiantil Web (SAEW)". The population was characterized according to its gender, ethnicity and place of provenance in comparison with general population.

A comparative analysis of the grades obtained in the admission test "Ser Bachiller" was carried out among the students belonging to vulnerable groups and students belonging to the general population. For this analysis, data from the matrix of admitted students was used, data which was delivered by the SENESCYT to the EPN.

An accompanying program was proposed to a group of students belonging to vulnerable groups who were part of the inclusion project of the "Política de Cuotas". The program consisted of: selection of target population, selection of tutors, planning, execution, and control.

Out of the universe of vulnerable students (128 students), 45 people were selected, considering a homogeneous group of gender and ethnicity, who represented $35 \%$ of the total of beneficiary students. In Fig. 1 , a block diagram of the procedure for selection of the target population is presented. Then, the invitation was sent to all the selected people, through an email to participate in the first meeting. During this meeting objectives, scope and development of the model were presented. In addition, the formal registration of students wishing to participate was carried through.

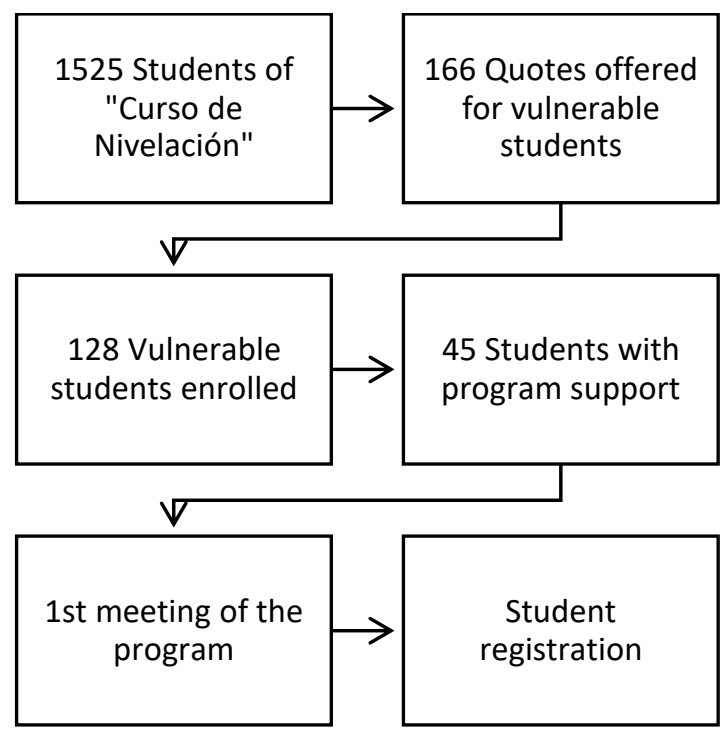

Fig 1. Diagram for the selection of the target population 
Form the 45 students selected (35\% of the students from vulnerable groups), are composed of $54 \%$ women and $46 \%$ men.

For the selection of tutors, students of the EPN of higher semesters were sought out, these students needed to cover hours of community outreach, which is a requirement for graduation. For this, a call was sent through the institutional website of the EPN, social networks and through posters placed in each of the different faculties.

The aspirants for tutors were interviewed with the objective of determining if they had the predisposition and the time for the project. Furthermore, the candidates gave proof of knowledge of the subject they wanted to teach to verify the level of preparation they had.

The management of the accompaniment program consisted of conventional classes to small groups and queries through social networks. The four subjects that the students must pass in the "Curso de Nivelación" were considered: Fundamentals of Mathematics, Fundamentals of Chemistry, Fundamentals of Geometry and Trigonometry; and, Physics.

The additional classes lasted two hours and were set in the schedule presented in Table 1. The schedule was divided in two groups because the "Curso de Nivelación" has two timetables (7:00 a.m. to 1:00 p.m. and 2:00 p.m. to 8:00 p.m.).

Regarding to queries through social networks, groups were created among the students, the tutors and the head lecturer. Through these groups, tutors were able to solve problems and answered concerns immediately about any subject. The social network used for this purpose was Whatsapp. In Fig. 2, an example of virtual queries is presented.

TABLE 1 .

Schedule Additional Classes

\begin{tabular}{|l|l|c|c|c|}
\hline SCHEDULE & MONDAY & TUESDAY & THURSDAY & FRIDAY \\
\hline $\begin{array}{l}\text { 11:00 a.m. to } \\
\text { 13:00 p.m. }\end{array}$ & Geometry & Mathematics & Chemistry & Physics \\
\hline $\begin{array}{l}\text { 14:00 p.m. to } \\
\text { 16:00 p.m. }\end{array}$ & Geometry & Mathematics & Chemistry & Physics \\
\hline
\end{tabular}

The program was supervised by lectures of the "Curso de Nivelación", who were responsible for training the tutors of each subject. Each week, the lectures helped the tutors with guidelines on the classes to be taught and, if necessary, doubts were clarified. The supervision had a record of attendance of both students and tutors.

In order to evaluate the results, the grades obtained in the four subjects (Mathematics, Geometry, Physics, and Chemistry) by three population groups were analyzed comparatively: vulnerable students with program support, vulnerable students without the program, and the general population.

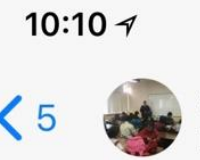

Clases Adicionales 2017 B

Ily, Ing. Sandoval, Jonhatan, Joseph, Vaness.

$$
\text { Sun, Jan } 21
$$

+593999092026 \%Rodman PC $\Leftrightarrow$

porfas alguien que me ayude en el 108 de geometria del cuaderno de trabajo porfavor

\section{$19: 28$}

+593978810674 Santiago Seeker

hola Rodman, pronto estaré

subiendo la solución a tu ejercicio.

+593978810674 Santiago Seeker

+593999092026 Rodman PC

porfas alguien que me ayude en el $108 \mathrm{de}$

geometria del cuaderno de trabajo porfavor
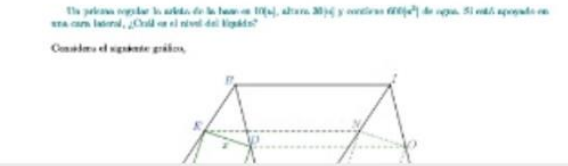

pdf Ejercicio 108.pdf

2 pages $\cdot 128 \mathrm{~KB} \cdot \mathrm{pdf}$ $20: 02$

Fig. 2. Social network screenshot

In the fieldwork, a survey was conducted to all the students who were considered in the program. The survey was based on questions about attendance, and, in case of non-attendance, to know about the reasons that motivated the desertion of the classes. This allowed us to evaluate the development of the program.

\section{RESULTS' ANALYSIS}

\section{A. Population characterization}

\section{- Enrollment and dropout}

In the academic period 2017B, the number of students belonging to vulnerable groups who dropped out their studies are $70(58 \%)$; the dropout is generated in two stages, the first stage related to the student's decision to assist to classes, called "vulnerable students not enrolled" (38 students); and the second stage related to the low academic performance, called "inactive students" (students who did not record any grades).

The description of the permanence of vulnerable students in the university is presented in Table 2. 
TABLE II

Description of the permanence of vulnerable students

\begin{tabular}{|c|c|c|c|c|}
\hline $\begin{array}{c}\text { Quotes } \\
\text { offered for } \\
\text { vulnerable } \\
\text { students }\end{array}$ & $\begin{array}{c}\text { Vulnerable } \\
\text { students not } \\
\text { enrolled }\end{array}$ & $\begin{array}{c}\text { Vulnerable } \\
\text { students } \\
\text { enrolled }\end{array}$ & $\begin{array}{c}\text { Inactive } \\
\text { students }\end{array}$ & $\begin{array}{c}\text { Active } \\
\text { vulnerable } \\
\text { students }\end{array}$ \\
\hline 166 & 38 & 128 & 32 & 96 \\
\hline
\end{tabular}

- Gender, ethnia, place of origin

In the characterization of the vulnerable population in the "Curso de Nivelacion" of the "Escuela Politécnica Nacional", it was found that of the 166 students, the $69 \%$ correspond to women; the population of vulnerable students is characterized by having mostly women, as shown in the Fig. 3.

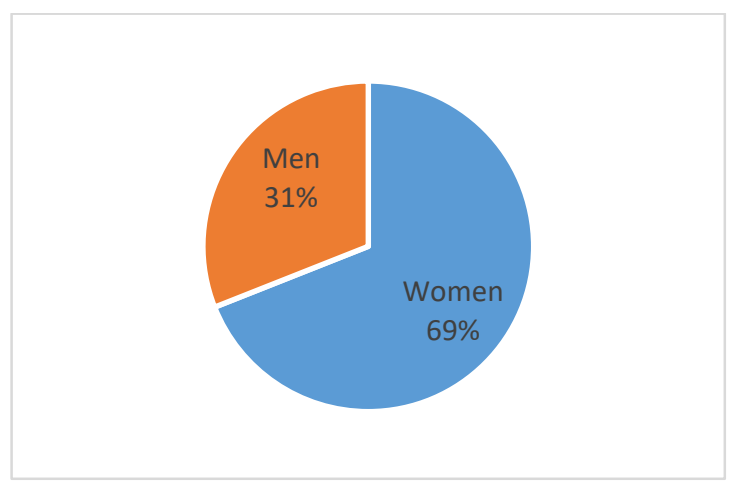

Fig. 3. Vulnerable students by gender

The population of vulnerable students is characterized by having mostly "mestizos" $(78 \%)$, and the second ethnia group is "indígenas" (15\%), as shown in Fig. 4.

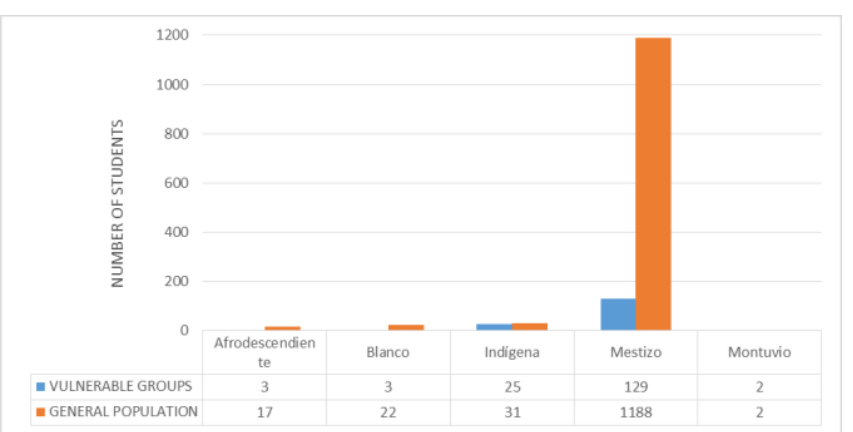

Fig 4. Vulnerable population by ethnicity.

The $63 \%$ of the students belong to the province of Pichincha, 9\% belong to the province of Imbabura, and the remaining $28 \%$ belong to different provinces of Ecuador.

It is evident that $37 \%$ of the students who belong to vulnerable groups, and are admitted to the EPN careers are from provinces outside the province of Pichincha, where the university is located. This can be seen in the Fig. 5 .

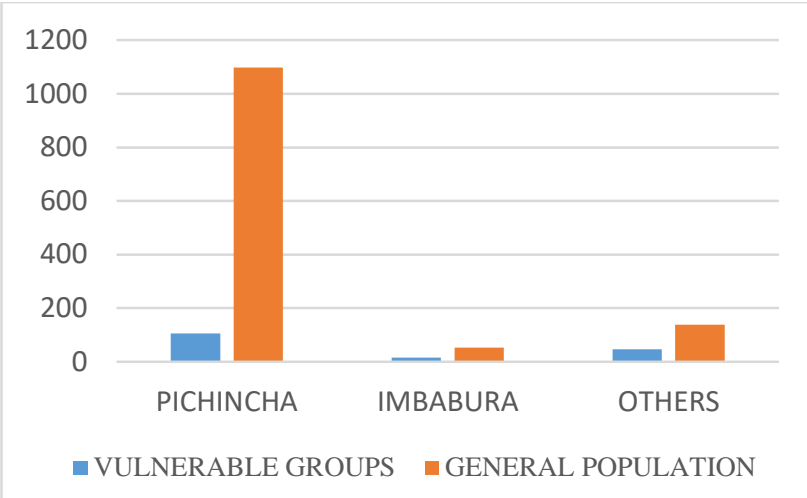

Fig 5. Province of origin of students of "Política de Cuotas"

The Fig. 5, show that the second province of origin of the vulnerable students is Imbabura, the province of Imbabura has in its population high percentages of the indigenous ethnic group. The relationship between ethnic and province of origin is close.

\section{- Admission test grade.}

From the comparative analysis of grades obtained in the "Ser Bachiller" admission test (Fig. 6), the average grade of students belonging to the general population is higher than the average grade of students from vulnerable groups by 66 points. This indicates that students belonging to vulnerable groups start their higher education in unequal conditions.

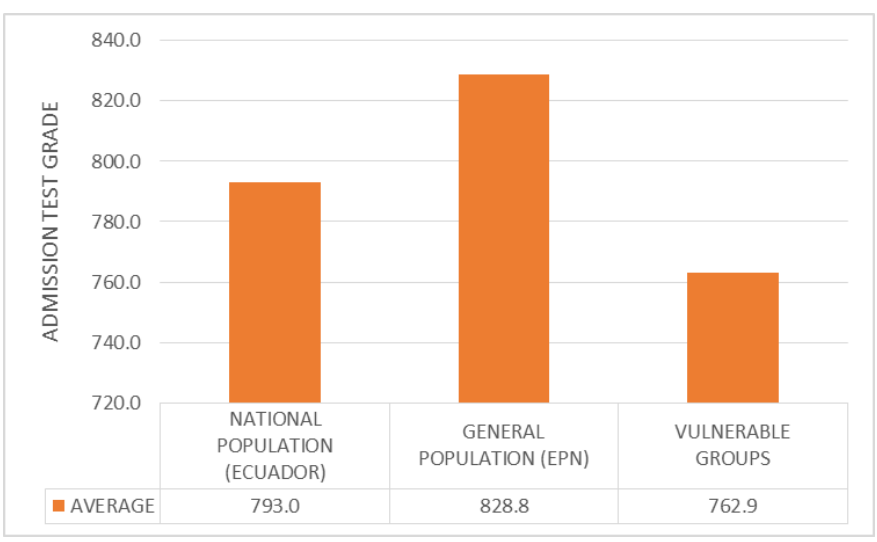

Fig 6. Admission test average grade.

Due to the EPN is the best university in Ecuador, it is required to have high scores in the admission test, the Fig. 7 show that the grades of the general population is higher than the grades of the national population, also it is evident that the students of vulnerable groups have grades lower than the national population, therefore through the "Politica de Cuotas" project these students can access to the EPN. 


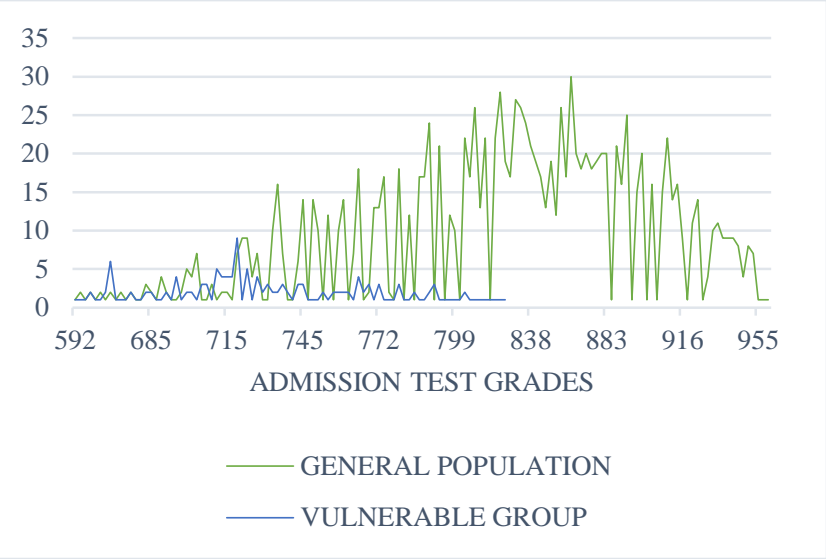

Fig 7. Frequency of admission test grade.

\section{B. Results of the accompanying program}

- Subjects'grades analysis.

It was found that the average grades obtained by the students who are part of the program is higher than the average grade of the students who did not have the support from the program. In the subject of Fundamentals of Mathematics the average is higher by $10 \%$, in the subject of Geometry and Trigonometry by $9 \%$, in the subject of Physics by $12 \%$, and in the subject of Fundamentals of Chemistry by $0.8 \%$. The grades in the "Curso de Nivelación" showed in the Fig. 8.

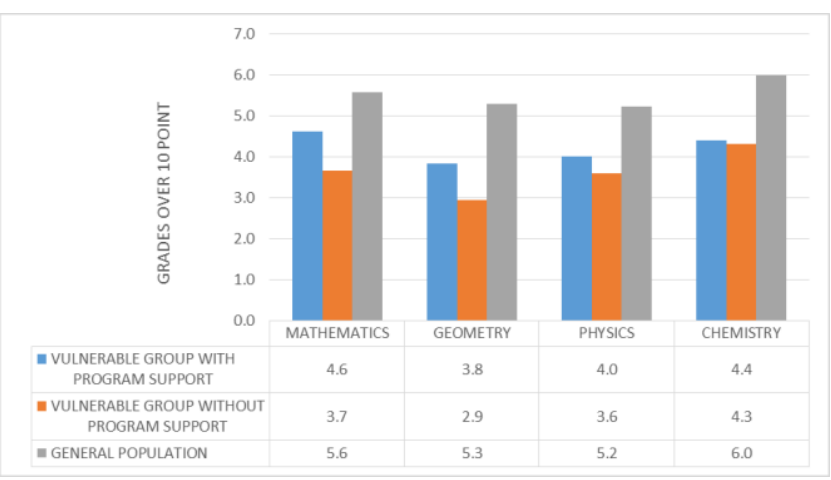

Fig 8. Student performance according to the population group

\section{- $\quad$ Survey results}

From the follow-up and attendance control of students, it was determined that the implemented program is affected by the lack of attendance to classes. Fig. 9 presents the percentages of abandonment to face-to-face tutorials by subject. In the subject of Geometry and Trigonometry it was determined that $60 \%$ of the students abandoned the tutorials, when considering the subject of Fundamentals of Chemistry it was determined that the percentage of abandonment was $80 \%$, in the subject of Fundamentals of Mathematics the abandonment was of $87.7 \%$ and finally in the matter of Physics the abandonment was $93.3 \%$.

The percentage of dropout from students who participated in the program, in all subjects exceeded $60 \%$, however, it is evident that the subject with the least abandonment percentage is Geometry and Trigonometry, although this is the subject with the highest failure rate. This analysis shows the prioritizing process made by the students regarding the different subject.

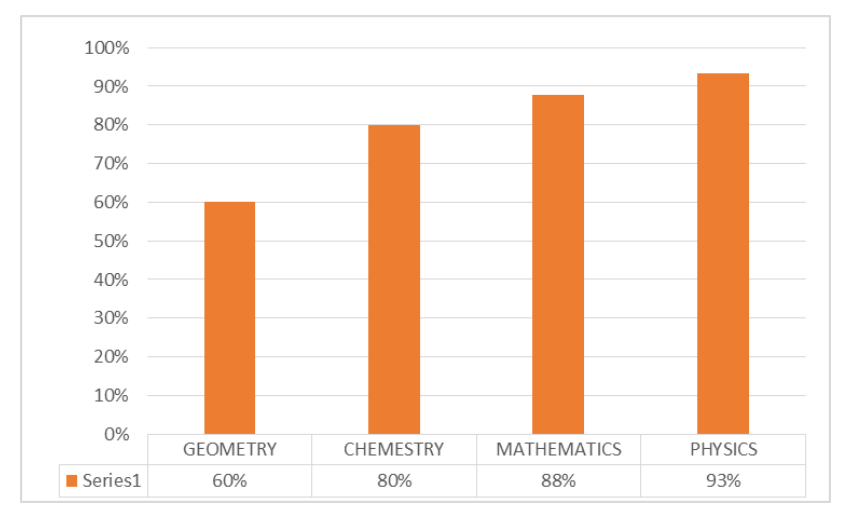

Fig. 9. Dropout percentage per subject

$95 \%$ of the students who were part of the program made use of the virtual tutorials during the whole period of development of the program, even after having abandoned the face-to-face tutoring. Accompaniment through social networks was more successful than face-to-face tutoring due to the lower cost it represented to students.

From the survey conducted to the 45 students of the follow-up program, the answers for each question were analyzed.

Question 1: Do you regularly attend to in-person support classes?

It is observed that one third of the students completed the follow-up model in at least one subject. Approximately $13 \%$ of the students in the program canceled the enrollment in the "Curso de Nivelación", as shown in Fig. 10.

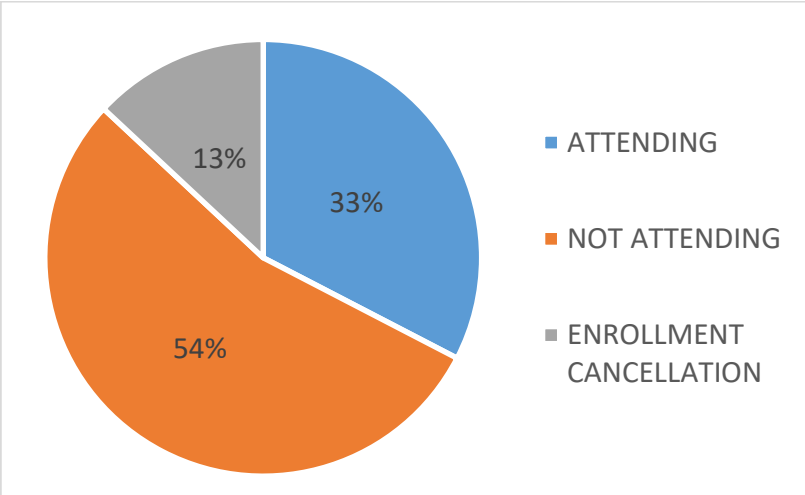

Fig. 10. Attendance percentage

Question 2: Indicate the reasons why you dropped out of the face-to-face support classes.

Among the reasons why the students left the program was the lack of preparation of the tutor, because they had no pedagogical preparation, since tutor were students of higher levels of engineering and science careers. Another group of students indicated that they left the program because of financial problems. Some of the students from vulnerable groups had to work or help their parents in their 
work activities. Lack of time is another reason for students not following with the program because apart from the six hours a day that they dedicate to their regular classes, the student must allocate two additional hours for tutoring, considering that they also perform other activities, even non-academic ones (Fig. 11).

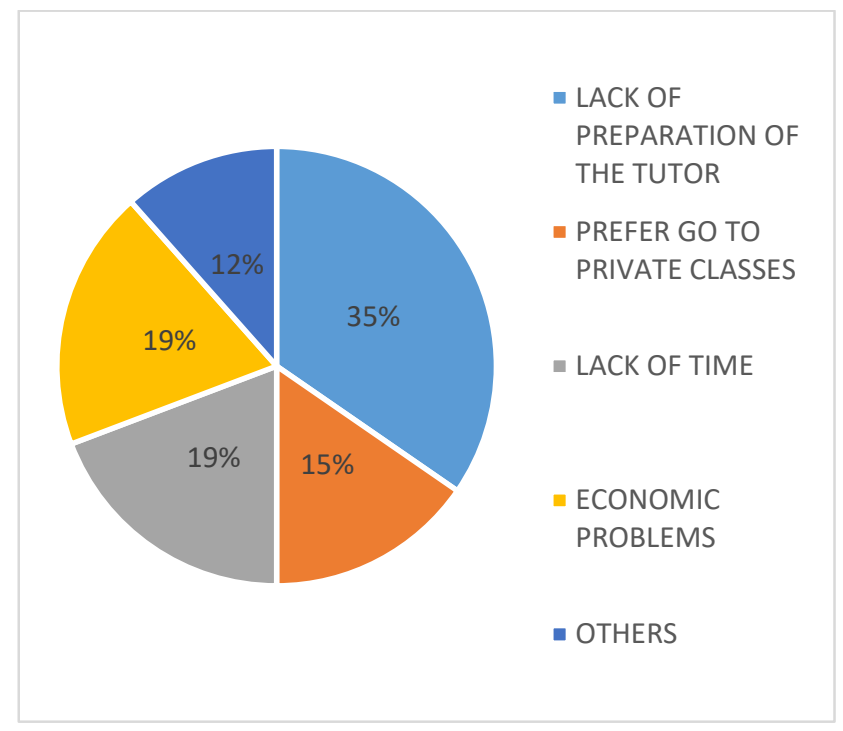

Fig. 11. Causes of abandonment

\section{CONCLUSIONS AND RECOMMENDATIONS}

The population of vulnerable students is characterized to have in its majority women, "mestizos" and who come from the province of Pichincha.

The average score on the admission exam from students in vulnerable groups is lower than the average score from student belonging to the general population. This is a factor that mainly affects academic performance. In addition, there are psychological, social and economic factors that vulnerable students confront every day.

The implementation of this program within a group of students belonging to vulnerable groups, showed positive results, in comparison to other. However, these results were not enough to ensure that these students will pass the leveling course of the "Escuela Politécnica Nacional."

The virtual tutorials are a key element of the program. These tutorials allow students to maintain direct communication with the tutors, and solve doubts immediately and efficiently.

It is necessary that the implementation of the program be integral, emphasizing face-to-face and virtual tutorials simultaneously. Additionally, the program needs to be linked with a socioeconomic support system (government scholarships), in order to guarantee the permanence and success of students in vulnerable groups in the leveling course of the "Escuela Politécnica Nacional."

The main problem detected in the program is the lack of attendance of students in the face-to-face tutorials in all subjects, mainly because the tutors of the program are students of advanced semesters. This shows that the mastery of a subject is not enough to teach it, and that it is necessary to train tutors in appropriate teaching strategies.

The accompaniment program must be carried out under the supervision of DFB lectures, not using students of higher semesters as tutors.

It is recommended that students from the group of "Política de Cuotas" take a test so that the selection of students is based on academic performance and not randomly.

It is recommended to improve the identification algorithm of the SENESCYT which is used for the selection of students of the "Política de Cuotas" group.

\section{ACKNOWLEDGMENT}

We appreciate the information provided by the SENESCYT that allowed us to carry out this accompaniment program, to the EPN for the opportunity to carry out the project of linkage PVS-2017-014 Follow-up and support to the students of vulnerable groups and to the DFB for the provided facilities of resources and time to develop this project of accompaniment and obtain the results achieved and exposed in the conclusions and recommendations.

\section{REFERENCES}

[1] Beltrao, F., Monteiro, J., Gómez, I., Pajares, E., Paredes, F., \& Zúñiga, Y. (2014). Derechos Humanos de los Grupos Vulnerables. Barcelona: EDO-SERVEIS.

[2] Duryea, S., Lam, D., \& Levison, D. (2007). Effects of Economic Shocks on Children's Employment and Schooling in Brazil. Journal of Development Economics, 188-214.

[3] Bashir, S., \& Luque, J. (2018). Equity in Tertiary Education in Central America : An Overview. Policy Research Working Papers.

[4] OEI. (2010). La Educación que queremos para la generación de los bicentenarios. Madrid: Cudipal.

[5] Gairín, J., Castro, D., \& Bosco, J. (2014). ACCESO Y PERMANENCIA DE GRUPOS VULNERABLES. (págs. 1-35). Barcelona: Universidad Autónoma de Barcelona.

[6] Asamblea Constituyente. (2008). Constitución de la República del Ecuador. Montecristi: Asamblea Constituyente.

[7] SENESCYT. (2015). Reglamento del Sistema Nacional de Nivelación y Admisión. Quito: SENESCYT.

[8] Canales, A., \& de los Ríos, D. (2009). Entendiendo la permanencia de estudiantes vulnerables en el sistema universitario. Santiago de Chile: Universidad Santiago de Chile.

[9] Canales, A., \& de los Ríos, D. (2009). Entendiendo la permanencia de estudiantes vulnerables en el sistema universitario. Santiago de Chile: Universidad Santiago de Chile.

[10] Cruz, A., \& Díaz, M. (2012). Apoyo a estudiantes con discapacidad desde la tutoría. Ciudad de México: Universidad Veracruzana. 